\title{
The Psychometric Properties of a Brief Dutch Version of the Reinforcement Sensitivity Theory of Personality Questionnaire
}

\author{
Serafine Dierickx (D), Dirk Smits ${ }^{1,2}$ (D), Philip J. Corr ${ }^{3}$, Penelope Hasking ${ }^{4}$ (D), and \\ Laurence Claes ${ }^{1,5}$ \\ ${ }^{1}$ Faculty of Psychology and Educational Sciences, KU Leuven, Belgium \\ ${ }^{2}$ Odisee - University of Applied Sciences, Brussels, Belgium \\ ${ }^{3}$ Department of Psychology, University of London, UK \\ ${ }^{4}$ School of Psychology, Curtin University, Perth, WA, Australia \\ ${ }^{5}$ Faculty of Medicine \& Health Sciences (CAPRI), University of Antwerp, Belgium
}

\begin{abstract}
Introduction: The Reinforcement Sensitivity Theory of Personality Questionnaire (RST-PQ) has its roots in the revised reinforcement sensitivity theory of personality. Objectives: This study investigated the reliability and validity of the Dutch translation of the RST-PQ and proposed a brief version. Methods: A sample of 603 Belgian and Dutch adults completed the RST-PQ, and to assess convergent and divergent validity, a subgroup also completed other personality and symptom questionnaires. Results: A confirmatory factor analysis (CFA) confirmed the a priori six-factor structure of the RST-PQ, similar to other translations. However, this model did not satisfy the requirements of an acceptable fit. Therefore, a brief version of the RST-PQ (B-RST-PQ) was developed. In line with the aims of the RST-PQ, a CFA showed an acceptable fit for the six-factor model of the B-RST-PQ. The B-RST-PQ obtained good reliability coefficients of the six scales and high correlations with the original RST-PQ. Conclusion: The B-RST-PQ seems to be a valid and reliable instrument for future research.
\end{abstract}

Keywords: revised reinforcement sensitivity theory, Reinforcement Sensitivity Theory Personality Questionnaire, psychometrics, behavioral inhibition, behavioral approach

\section{The Reinforcement Sensitivity Theory}

Personality development has long been hypothesized to be influenced by specific brain systems (e.g., Eysenck, 1960; Gray, 1970). Extensive research has shown the importance of the reinforcement sensitivity theory (RST; Gray, 1982) in our understanding of the structure and causation of personality (Corr, 2008). The theory postulates that the human personality can be explained by neurobiological systems that regulate appetitive and aversive motivation. The most recent version of the theory proposes five systems (Corr \& McNaughton, 2012; Gray \& McNaughton, 2000). Two valuation systems weigh the gains and losses that stem from a specific situation (e.g., being promoted). Three brain circuit systems represent the motivational output in reaction to specific stimuli: the behavioral approach system (BAS), the behavioral inhibition system (BIS), and the fight-flight-freeze system (FFFS).

\section{The Behavioral Approach System}

The BAS represents the coordination of reactions to all conditioned and unconditioned stimuli of reward or "attractor stimuli" (Corr \& McNaughton, 2012; Pickering \& Smillie, 2008). The strength of reaction toward a stimulus can be defined as the individual sensitivity to BAS (Corr, 2008; Gray \& McNaughton, 2000). BAS is assumed to coordinate specific subprocesses that elicit the behavior of impulsivity and extraversion (Smillie et al., 2006). 


\section{The Behavioral Inhibition System}

The BIS is considered a conflict detector and regulator (Corr, 2008) and, when activated, the detection of conflict leads to a process of conflict resolution, during which time a state of anxiety is generated. This serves the function of biasing all ongoing psychological processes in this negative emotional state (Corr, 2006). Individual differences in the reactivity of BIS are assumed to underlie trait anxiety (Gray, 1982).

\section{The Fight-Flight-Freeze System}

The FFFS is responsive to both conditioned and unconditioned aversive stimuli or "repulsor stimuli" (Corr \& McNaughton, 2012). Upon activation, its outputs are dependent on both contextual stimuli and earlier learning behavior (Krupić, 2017). Individual differences in the activity of FFFS are presumed to underlie fear (Smillie et al., 2006).

\section{The Interdependence Between the Systems}

In the revised reinforcement sensitivity theory (r-RST; Gray \& McNaughton, 2000), there is still a lack of clarity regarding the relation between the separate systems (Bijttebier et al., 2009). The Separable Subsystems Hypothesis refers mostly to the original theory, describing BAS and BIS/FF(F)S as two independently operating systems (Corr, 2001). However, the joint subsystems hypothesis presumes that, although BIS and BAS operate as two interdependent systems, they jointly influence behavior that is seen as a product of activated systems - this is typical in many human situations (e.g., academic examination; Corr, 2001). Finally, the Velocity Hypothesis assumes that either an approach or an avoidance motive can lead to either positive or negative affect (Carver, 2004; Harmon-Jones, 2003) - this outcome is determined not by the kind of motive but rather by the efficiency of the action (i.e., whether it achieves its goal). At present, there is no consensus as to the relationships between these subsystems. Corr (2001) suggested that a combination of the hypotheses is viable depending on the specific demands of the situation (i.e., some situations entail signals of both potential reward and punishment, e.g., disappointment, as might be seen in a romantic encounter).

\section{RST-PQ Development}

The RST-Personality Questionnaire (RST-PQ; Corr \& Cooper, 2016) was developed to assess the r-RST. This development was motivated by the fact that other RST measures were either based on the original theory or, if based on r-RST, do not provide an adequate measurement instrument, especially related to the complexity of the BAS (for an overview, see Corr, 2016).

The item selection was initially organized by composing a large pool of items, all answering to three conditions: (1) each item should be easily traced back to an essential theoretical concept, (2) ambiguity linked to emotional words should be avoided, and (3) several methods should be used to generate the items (Corr \& Cooper, 2016). The items stemmed from other frequently used RST instruments and from qualitative responses to defensive and approach situations (Corr, 2016). After exploratory and confirmatory analyses, the original pool was fine-tuned to 65 items measuring six scales.

First, the FFFS was initially purposed as a multidimensional scale described as the motivation to avoid aversive stimuli by fighting, avoiding, or freezing/standing still. The scale consisted of three thematic facets that encaptivated the theoretical process of defensive fight, flight, and freeze. Because it was not successful to include defensive fight within FFFS (Corr, 2016; Corr \& Cooper, 2016), the FFFS was represented as a unidimensional scale comprising flight, freeze, and some active avoidance items. A seventh scale of defensive fight was proposed by Corr and Cooper (2016) but was found problematic and is therefore generally disregarded (Eriksson et al., 2019; Krupic et al., 2016; Pugnaghi et al., 2018; Wytykowska et al., 2017). Therefore, in this article, this scale will be referred to as flight-freeze system (FFS). Active avoidance is provoked when the threat is distant enough to not constitute an immediate danger. When the threat is perceived as closer but still avoidable, Flight is introduced. It decreases the risk of confrontation by respectively avoiding or fleeing the epicenter of the threat (Corr \& McNaughton, 2012; Pickering \& Smillie, 2008). Freezing is elicited when the epicenter of the threat is unavoidable, making an escape impossible. Freezing, also described as "playing dead," is an attempt to not catch the attention of the threatening stimuli. FFS was found to correlate significantly positive with neuroticism, the Carver and White BIS scale, fear as measured by the fear survey schedule (FSS; Wolpe \& Lang, 1964), negative affect, and gender (Corr \& Cooper, 2016; Pugnaghi et al., 2018; Wytykowska et al., 2017).

Second, BIS is a unidimensional scale defined as the motivation to cope with the conflict that arises when aversive stimuli must be approached. BIS consists of four thematic facets, motor planning interruption, worry (sometimes referred to as cautious risk assessment), 
Table 1. Overview of RST-PQ translations

\begin{tabular}{|c|c|c|c|c|c|c|}
\hline \multirow[b]{2}{*}{ Authors (year) } & \multirow[b]{2}{*}{ Translation } & \multirow[b]{2}{*}{ Sample N } & \multirow[b]{2}{*}{ Mean age (SD) } & \multirow[b]{2}{*}{ Method } & \multicolumn{2}{|c|}{ Fit indices } \\
\hline & & & & & $\mathrm{CFI}$ & RMSEA \\
\hline Eriksson et al. (2019) & Swedish & 320 & $43.75(14.46)$ & Six-factor CFA & .76 & .055 \\
\hline Krupić et al. (2016) & Croatian & 821 & $22.31(4.16)$ & Six-factor CFA & .93 & .055 \\
\hline Pugnaghi et al. (2018) & German & 527 & $26.97(7.44),{ }^{a} 26.31(7.50)^{b}$ & Six-factor CFA & .82 & .048 \\
\hline Wytykowska et al. (2017) & Polish & 1,512 & $39.41(13.16)$ & Six-factor CFA & .80 & .055 \\
\hline
\end{tabular}

Note. The six-factor CFA includes FFS, BIS, and the four BAS subscales. BAS = behavioral approach system; BIS = behavioral inhibition system; CFA = confirmatory factor analysis; $\mathrm{CFI}=$ comparative fit index; FFS = flight-freeze system; RMSEA = root mean square error of approximation; RST-PQ = Reinforcement Sensitivity Theory of Personality Questionnaire; SD = standard deviation. ${ }^{a}$ Males. ${ }^{b}$ Females.

obsessive thoughts, and behavioral disengagement, but these facets are merged into one scale as there was no psychometric support for a multidimensional scale (Corr \& Cooper, 2016). Motor planning interruption refers to the inhibition of motor programs when an avoidable threat is presented. Worry concerns the cognitive process of rumination that is accompanied by BIS activation. Obsessive thoughts, on the other hand, is the cognitive and emotional engagement with dangerous stimuli that are unidentifiable, unlocatable, or unavoidable. Behavioral disengagement is considered the cognitive and emotional withdrawal from contexts where such stimuli can be encountered (Corr \& Cooper, 2016). Corr and Cooper (2016), Pugnaghi et al. (2018), and Wytykowska et al. (2017) reported positive correlations between RSTPQ BIS and neuroticism, fear (FSS), trait and state anxiety, and BIS as measured using the BIS/BAS scales (Carver \& White, 1994).

Finally, the BAS is a multidimensional scale that represents the four theoretical subprocesses in getting a reward: reward interest is defined as the openness to new opportunities and exploring behavior based on the incentive motivation toward appetitive stimuli; goaldrive persistence (GDP) is described as the preservation of positive motivation in times when appetitive stimuli are not available immediately; reward reactivity is explained as the creation of an opportunity for and experience of appetitive stimuli; and impulsivity is defined as the fast approach to appetitive stimuli that does not require any planning (Corr \& Cooper, 2016). The multidimensionality of BAS is both theoretically (Smillie et al., 2006) and empirically (Carver \& White, 1994) supported. In earlier studies, all RST-PQ BAS scales were positively related to extraversion and the three BAS scales of the BIS/BAS. GDP was significantly positively associated with conscientiousness, as reward interest was with openness. RST-PQ impulsivity was highly related to other measures of impulsivity (BIS-11). All BAS subscales were also positively associated with positive affect (Corr \& Cooper, 2016; Pugnaghi et al., 2018; Wytykowska et al., 2017).
Corr and Cooper (2016) were the first to validate the RST-PQ. The fit of their confirmatory factor analysis (CFA) was not completely satisfactory given that at least one of the fit indices was rather low (comparative fit index [CFI] = .87). So far, translations have confirmed the proposed sixfactor model with similar fit indices (Table 1). Corr and Cooper (2016) reported adequate internal consistency coefficients for the different scales ( $\alpha$ ranging from .74 to .93) and correlations ranging from -.08 to .44 . The $\alpha$ coefficients of the original RST-PQ scales, as well as the correlations among the subscales, can be found in Table 2 . The convergent and divergent validity of the RST-PQ with other personality measures has been shown to be adequate in various studies (Corr \& Cooper, 2016; Pugnaghi et al., 2018; Wytykowska et al., 2017).

Table 2. Pearson correlations and descriptive statistics for the Dutch RST-PQ scales (first row) and for the original RST-PQ scales (second row; Corr \& Cooper, 2016)

\begin{tabular}{lcccccc}
\hline & 1 & 2 & $3 a$ & $3 b$ & $3 c$ & $3 d$ \\
\hline 1. FFS & - & $.46^{\star \star}$ & $-.18^{\star \star}$ & .03 & $.20 * \star$ & .08 \\
& & .44 & -.08 & .07 & .21 & .16 \\
2. BIS & & - & $-.23^{\star *}$ & -.04 & $.09 *$ & .07 \\
& & & -.06 & -.06 & .16 & .17
\end{tabular}

3. BAS

3a. Reward interest

3b. GDP

$.46^{\star \star} \quad .40^{\star \star} \quad .32^{\star \star}$

$\begin{array}{rrr}.41 & .48 & .43 \\ -\quad .43^{* *} & .12^{\star *}\end{array}$

3c. Reward reactivity

$.33 \quad .02$

3d. Impulsivity

$\begin{array}{llllllll}\alpha & .73 & .94 & .81 & .81 & .73 & .76\end{array}$

$\begin{array}{lllllll}.78 & .93 & .75 & .86 & .78 & .74\end{array}$

\begin{tabular}{lllllll}
$\omega$ & .73 & .94 & .82 & .82 & .74 & .77 \\
\hline
\end{tabular}

Note. $N=603 .{ }^{*} p<.05,{ }^{*} p<.01$. BAS = behavioral approach system; BIS = behavioral inhibition system; FFS = flight-freeze system; GDP = goal-drive persistence; RST-PQ = Reinforcement Sensitivity Theory of Personality Questionnaire. 


\section{Translation Process}

So far, a Dutch version of the RST-PQ does not exist. The aim of the present study is to translate the RST-PQ to Dutch, to investigate its psychometric features, and to establish its validity within a Dutch-speaking community sample. The use of the RST-PQ instrument is currently limited to research purposes. The instrument has the potential to be extended to more higher-stakes settings such as for assessment purposes, but this is disregarded in this research article, as we first want to introduce the questionnaire in the Dutch-speaking research context. The RST-PQ is suitable for translation as its items are easily adaptable (universal) and suited for the multistep approach to questionnaire translation (Behr \& Shishido, 2016).

After obtaining written permission from Dr. Corr, the RST-PQ was translated into Dutch. Koen Luyckx and L. C. independently translated all items. They compared their translations and searched for a mutual interpretation when their translated items differed. After a conclusive Dutch translation was obtained, the items were back-translated into English without reference to the original wording by two independent researchers. Finally, two independent doctoral students linked the translated items to the original items to assure consistency.

\section{Study Aims}

The aim of the study was to investigate the psychometric properties of the Dutch version of the RST-PQ in a Dutchspeaking community sample. Currently, the RST-PQ is exclusively used for research purposes, and the sample was therefore collected in the general population. The factor structure and reliability of the RST-PQ scales were tested, as well as the validity of the questionnaire by correlating the RST-PQ with other personality (BIS/BAS scales, Big Five Inventory [BFI]) and symptom (Symptom Checklist-90 [SCL-90]) questionnaires.

Based on the existing literature, we hypothesize that the latent six-factor structure of the RST-PQ as found by Corr and Cooper (2016) will be replicated (CFI < .90; root mean square error of approximation [RMSEA] $=.05-.08)$. Additionally, we tested a two-factor structure (comprising $\mathrm{BIS}$ /FFS and BAS) as this model is in line with the original theory by Gray (1982) and by Gray and McNaughton (2000). We hypothesize that the two-factor model will show a less adequate fit in comparison to the six-factor model. We expect all scales to be reliable (i.e., $\alpha>.70 ; \omega>$ .70) and that the female group will score significantly higher on FFS, BIS, and RR, as has been found in previous research (Ma-Kellams \& Wu, 2020; Segarra et al., 2014).
BIS is expected to correlate positively with BIS (BIS/ BAS scales), neuroticism, and anxiety (SCL-90), but not with phobic anxiety. A negative correlation is anticipated between BIS and extraversion. FFS is also hypothesized to correlate with neuroticism and anxiety, but we expect to find smaller effect sizes in comparison to BIS. FFS is additionally expected to correlate positively with gender. Overall, BAS is hypothesized to strongly and positively relate to extraversion and the BAS subscales of Carver and White (1994). Within the subscales, reward interest is thought to correlate positively with openness. A positive link is expected between GDP and conscientiousness (Corr \& Cooper, 2016; Pugnaghi et al., 2018; Wytykowska et al., 2017).

In case of a good model fit, we would consider retaining the current RST-PQ model, but based on previous studies, we expect an inadequate model fit. Consequently, a brief version of the RST-PQ (B-RST-PQ) will be developed with a more acceptable model fit for a six-factor CFA (CFI >.90; RMSEA <.08), but with at least similar convergent validity and reliability indices. Its psychometric features will be investigated in the same way as described for the RST-PQ.

\section{Methods}

\section{Participants}

The sample consisted of 603 adult Dutch-speaking respondents who voluntarily participated, of whom 490 were female $(81.3 \%)$ and 113 participants were male (18.7\%). The mean age of the participants was $27.53(S D=$ $11.84)$. Males $\left(M_{\mathrm{age}}=31.97, S D=14.53\right)$ were significantly older than females $\left(M_{\text {age }}=26.51, S D=10.89 ; t(142.372)=\right.$ $3.76, p<.01)$. Concerning educational level, $0.83 \%(n=5)$ did not complete secondary education, $36.48 \%(n=220)$ completed high school, 22.22\% ( $n=134)$ completed higher education outside the university, and $40.46 \%(n=244)$ completed university education.

A subset of 110 participants completed the BIS/BAS scales $\left(70.91 \%\right.$ females, $\left.M_{\text {age }}=36.85, S D=13.62\right), 85$ participants the BFI $\left(65.88 \%\right.$ females, $M_{\text {age }}=37.55, S D=$ $13.41)$, and 84 people the SCL-90 (65.48\% females, $M_{\text {age }}=$ 37.40, $S D=13.42)$.

\section{Materials}

The RST-PQ (Corr \& Cooper, 2016) consists of 65 items rated on a 4-point rating scale ranging from 1 (not at all accurate) to 4 (highly accurate) to indicate for each item: "How accurately does each statement describe you?" The 
questionnaire consists of one unitary BIS scale, one unitary FFS scale, and four BAS subscales: reward interest, GDP, reward reactivity, and impulsivity (Corr \& Cooper, 2016; see the RST-PQ Development section).

To assess convergent/divergent validity between the RST-PQ and other personality and symptom measures, the following instruments were administered.

The BIS/BAS scales (Carver \& White, 1994) were used to assess individual differences in sensitivity toward punishment and reward. The BIS/BAS scales consist of 24 items to be rated on a 4-point Likert scale ranging from 1 (strongly disagree) to 4 (strongly agree). The BIS/BAS scales include one unitary BIS scale $\left(n_{\text {items }}=7 ; \alpha=.84\right.$ in the present study), three BAS subscales such as reward responsiveness $\left(n_{\text {items }}=5\right.$; $\alpha=.62)$, drive $\left(n_{\text {items }}=4 ; \alpha=.81\right)$, and fun-seeking $\left(n_{\text {items }}=4\right.$; $\alpha=.64)$, and four filler items.

The BFI (John \& Srivastava, 1999) includes 25 items scored on a 5-point rating scale ranging from 1 (strongly disagree) to 5 (strongly agree). The questionnaire assesses five subscales. The current study found similar Cronbach's $\alpha$ coefficients to Corr and Cooper (2016): openness ( $\alpha=$ $.80)$, conscientiousness $(\alpha=.73)$, extraversion $(\alpha=.87)$, agreeableness $(\alpha=.64)$, and neuroticism $(\alpha=.80)$.

The SCL-90 (Arrindell \& Ettema, 1981) consists of 90 items rated on a 5-point Likert scale ranging from 1 (not at all applicable) to 5 (strongly applicable). The questionnaire measures a wide array of symptoms. For this study, only the subscales "anxiety" (10 items; $\alpha=.89)$ and "phobic anxiety" (seven items; $\alpha=.90$ ) were used to assess, respectively, manifest anxiety and a disproportionate fear response toward a specific stimulus.

\section{Procedure}

Data were obtained through an online self-report survey in Dutch, programmed in Qualtrics, version 2017 (Qualtrics, Provo, UT). Invitations were e-mailed to small and medium business companies in Flanders. After reading and agreeing with the informed consent, respondents were requested to fill in the questionnaires at home or wherever they felt comfortable. The RST-PQ and other relevant questionnaires were gathered between January 2018 and January 2019. The survey included 123 respondents.

Starting November 2018, a smaller survey (sociodemographic questions + RST-PQ only) was additionally shared to collect data. It was emphasized that respondents who had already taken part in the previous survey were not allowed to complete this survey. The study was randomly distributed in Dutch-speaking student fora and other local companies to attract more respondents for the validation of the RST-PQ. In total, 480 people participated in the smaller survey. The study was approved by the ethical committee of the KU Leuven. In total, 603 respondents took part in the study.

\section{Statistical Analyses}

Statistical analyses were performed with SPSS version 26 for descriptive analyses, except for McDonald's $\omega$ coefficients that were calculated in R 4.0.0., and with Mplus version 8.3 for CFA. Model parameters were estimated with the weighted least square mean and variance adjusted (WLSMV) estimation algorithm as the data were categorical. Model fit was evaluated with $\chi^{2}$ values for absolute fit and with the CFI and RMSEA for a relative fit: CFI $>.95$ and RMSEA $<.06$ represented a good fit; CFI $>.90$ and RMSEA $<.08$ represented an acceptable fit (Hu \& Bentler, 1999).

To evaluate the reliability of the RST-PQ subscales, both Cronbach's $\alpha$ coefficients and McDonald's $\omega$ coefficients were calculated. McDonald's $\omega$ was chosen as the measure provides more accurate estimation of reliability and is less susceptible to problems with inflation and attenuation (Dunn et al., 2014). Cronbach's $\alpha$ was included to simplify comparison with earlier studies of the RST-PQ.

To assess convergent and divergent validity of the RSTPQ scales, Pearson correlation coefficients were calculated with other personality measures (BIS/BAS scales, BFI), symptom scales (SCL-90 anxiety and phobic anxiety), age, and gender. Correlations were evaluated as follows: correlations > . 1 - small, > .3 - moderate, and > .5 - strong.

An adaptation of the RST-PQ was developed since the original six-factor CFA did not obtain adequate model fit. One reason might be that the original RST-PQ model did not allow for items to load on more than one factor. In order to discover cross-loading items and to select more unidimensional items based on a fitting factorial model, we used an exploratory structural equation model (ESEM) analysis. ESEM incorporates both advantages of an exploratory factor analysis, by allowing every item to load on every factor, and CFA, by resulting in similar fit indices (Asparouhov \& Muthén, 2009). In an ESEM, only the number of factors is specified beforehand.

The ESEM solution was target rotated toward the target matrix, comprising a one for items belonging to that specific factor in Corr and Cooper's (2016) model and a zero otherwise. Consequently, items were selected with factor loadings equal to or higher than .50 on their factor and at the same time not showing a cross-loading equaling or exceeding .40 on any other factor. Within this subset, the five highest loading items were selected for each BAS scale and the FFS scale, and the 10 highest loading items for the BIS scale. The reason for selecting more items for the shortened BIS scale was that BIS is considered a 
uniform concept, which is also assessed by more items in the original scale, as opposed to the original FFS and BAS scales. After statistical selection, a content-specific analysis was done to ensure all facets of each scale were represented in the brief version. Every step in constructing the B-RST-PQ was monitored with changes in model fit according to CFI and RMSEA.

\section{Results}

\section{Validation of the Dutch Version of the Original RST-PQ}

\section{Factor Structure}

To investigate the factor structure of the RST-PQ two CFA models were fitted: a two-factor model that represents the original RST with all BAS-related items loading on one factor and all BIS- or FFS-related items loading on the other factor; and a six-factor model in line with the model presented by Corr and Cooper (2016).

First, the two-factor CFA did not show an adequate fit: $\chi^{2}$ $(2,015, N=603)=11,668.870, p<.001, \mathrm{CFI}=.595$, RMSEA $=.089$. A CFA was estimated with six factors, targeting the main dimensions of r-RST: $\chi^{2}(2,000, N=603)=$ $6,601.374, p<.001, \mathrm{CFI}=.807$, RMSEA $=.062$. The fit indices ${ }^{1}$ revealed a similar fit as the English RST-PQ (Corr \& Cooper, 2016; CFI = .87). In favor of comparability between the Dutch RST-PQ and other translated versions, the latter model will be further explored, although the CFI did not reach the criterion of adequate fit.

Pearson correlation coefficients were calculated (Table 2) to investigate the relations between RST-PQ scales. These correlations were similar to the correlations reported by Corr and Cooper (2016). BIS and FFS correlated moderately high $(r=.46)$ in the Dutch RST-PQ. All BAS scales correlated moderately positive with each other $(r=.32-.46)$, with an exception for GDP and impulsivity $(r=.12)$.

\section{Reliability and Gender Differences}

Cronbach's $\alpha$ coefficients of the different scales of the Dutch RST-PQ ranged between FFS $(\alpha=.73)$ and BIS $(\alpha=$.94; Table 2). Internal consistency of the RST-PQ scales could be considered adequate. Corr and Cooper (2016) reported similar $\alpha$ coefficients ranging from .74 to
.93. Additionally, McDonald's $\omega$ showed similar coefficients ranging from .73 to .94 .

As can be found in the Electronic Supplementary Material 3 (ESM 3), gender difference analyses revealed that the female group scored substantially higher on FFS, BIS, GDP, and reward reactivity.

\section{Convergent and Divergent Validity}

To determine convergent and divergent validity, Pearson correlation coefficients were calculated between the RSTPQ scales and other relevant personality and symptom questionnaires (Table 3).

FFS correlated with BIS (BIS/BAS; $r=.47$ ) and also showed positive associations with anxiety $(r=.28)$, conscientiousness $(r=.23)$, neuroticism $(r=.41)$, and gender $(r=$ .33). BIS correlated somewhat more with BIS (BIS/BAS; $r=$ $.55)$, anxiety $(r=.46)$, and neuroticism $(r=.57)$ in comparison to the FFS scale. BIS additionally correlated negatively with extraversion $(r=-.32)$ and age $(r=-.29)$. All BAS subscales showed a moderate-to-high correlation with the BAS scales from BIS/BAS $(r=.31-.69)$ and with extraversion $(r=$ .31-.69). Reward interest differentiated itself by a moderately positive relationship with openness $(r=.31)$. GDP and reward reactivity both correlated with conscientiousness $(r=$ .44 and $r=.32$, respectively). Impulsivity showed a moderately negative link with agreeableness $(r=-.33)$. The results show that the expectations were confirmed.

Overall, although these findings were in line with earlier studies (Corr \& Cooper, 2016; Eriksson et al., 2019; Krupić et al., 2016; Pugnaghi et al., 2018; Wytykowska et al., 2017), an acceptable model fit for the final six-factor CFA was not achieved. Moreover, the modification indices suggested cross-loadings for several items. Finally, the current RST-PQ is rather long for research practices. In light of these considerations, an adaptation was introduced to construct a brief RST-PQ with a well-delineated factor structure and reliable scales. The psychometric properties of the brief version were evaluated in an identical way and with the same sample as the long version.

\section{Development and Validation of the B-RST-PQ}

\section{Construction of the B-RST-PQ}

The original six-factor CFA $\left(\chi^{2}(2,000, N=603)=\right.$ $6,601.374, p<.001, \mathrm{CFI}=.807, \mathrm{RMSEA}=.062) \mathrm{did}$ not

\footnotetext{
For the benefit of comparison, model parameters for the six-factor CFA were additionally estimated with the ML (CFI = .719; RMSEA =.059) and ReML (CFI = .723; RMSEA = .057) algorithm. For this purpose, the items were handled as continuous variables instead of categorical variables. The fit seems less adequate in comparison to the WLSMV fit used in this article.
} 
Table 3. Pearson correlations between the Dutch RST-PQ and other measures of personality and symptoms

\begin{tabular}{|c|c|c|c|c|c|c|}
\hline & \multicolumn{6}{|c|}{ RST-PQ } \\
\hline & FFS & BIS & $\mathrm{RI}$ & GDP & $\mathrm{RR}$ & IMP \\
\hline \multicolumn{7}{|l|}{ BIS/BAS scales ${ }^{a}$} \\
\hline BIS & $.47^{\star \star \star}$ & $.55^{\star \star}$ & -.13 & .01 & .14 & -.18 \\
\hline BAS - DR & -.05 & -.04 & $.49 * \star$ & $.55^{\star \star}$ & $.53^{\star \star}$ & $.64^{\star *}$ \\
\hline BAS - FS & -.16 & .02 & $.54^{\star \star}$ & $.38^{* \star}$ & $.44 * \star$ & $.69 * *$ \\
\hline BAS - RR & .17 & .15 & $.31^{* \star}$ & $.41^{\star \star}$ & $.62 \star \star$ & $.38^{\star \star}$ \\
\hline \multicolumn{7}{|l|}{ SCL-90 } \\
\hline Anxiety & $.28^{\star \star}$ & $.46^{\star \star}$ & -.09 & .09 & .19 & $.27^{\star}$ \\
\hline Phobic anxiety & .15 & .20 & .00 & -.01 & .16 & .18 \\
\hline \multicolumn{7}{|l|}{$\mathrm{BF} \mathrm{I}^{\mathrm{C}}$} \\
\hline Openness & -.20 & -.05 & $.31 * \star$ & .09 & -.03 & .03 \\
\hline Conscientiousness & $.23^{\star}$ & -.14 & $.26^{\star}$ & $.44^{\star \star}$ & $.32 \star \star$ & -.06 \\
\hline Extraversion & -.14 & $-.32^{\star \star}$ & $.69 * \star$ & $.47^{\star \star}$ & $.31^{\star \star}$ & $.46^{\star \star}$ \\
\hline Agreeableness & .12 & -.14 & .07 & .09 & -.02 & $-.33^{\star \star}$ \\
\hline Neuroticism & $.41^{\star \star}$ & $.57^{\star \star}$ & -.07 & .13 & $.27 *$ & .06 \\
\hline Age & -.04 & $-.29 \star \star$ & $.13^{\star *}$ & -.03 & -.07 & -.08 \\
\hline Sex & $.33^{\star \star}$ & $.09 *$ & .02 & $.11 \star \star$ & $.14^{\star \star}$ & -.05 \\
\hline
\end{tabular}

BAS = behavioral approach system; BAS - RR = reward reactivity; BFI = Big Five Inventory; BIS = behavioral inhibition system; DR = drive; FFS = flight-freeze system; FS = fun seeking; GDP = goal-drive persistence; IMP = impulsivity; RI = reward interest; RR = reward reactivity; RR = reward responsiveness; RST-PQ = Reinforcement Sensitivity Theory of Personality Questionnaire; SCL-90 $=$ Symptom Checklist-90. aSample size $=110 .{ }^{b}$ Sample size $=84 .{ }^{\circ}$ Sample size $=85$. ${ }^{*} p<.05,{ }^{*} p<.01$.

obtain adequate fit. One reason might be that the original RST-PQ model did not allow for items to load on more than one factor. In order to discover cross-loading items and to select more unidimensional items based on a fitting factorial model, we used an ESEM. The fit indices of the six-factor ESEM can be found in Table 4 (Model 1).

The ESEM solution was target rotated to obtain a model comparable to the one of Corr and Cooper (2016). This model fitted the data adequately. Items were selected if their factor loadings were higher than .50 and did not cross load on any other factor. As described earlier, for each scale, the five highest loading items were selected. For BIS, the 10 highest loading items were selected. A CFA was performed on this reduced item set (Table 4, Model 2). One item remained problematic: Item 25 (I get a special thrill when I am praised for something I've done well) obtained a factor loading of .34 and was therefore excluded, resulting in Model 3. This model included 10 items for BIS, five items for FFS, and all BAS scales except reward reactivity (4).

The content specificity of the scales should not be disregarded. Hence, a manual control warranted that all facets were represented in the brief scales. Active avoidance (FFS) and motor planning interruption (BIS) facets were found lacking in the brief version. Therefore, the two highest loading items of these facets (items 52 and 58 for FFS and items 18 and 55 for BIS) were added to the brief scale (Model 4). After comparing the model fit, item 52 (There are some things that I simply cannot go near) was deleted again since it suffered high cross-loadings and it considerably

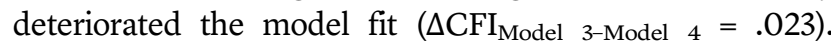

Table 4. Goodness-of-fit statistics of the confirmatory factor analytic and ESEM

\begin{tabular}{|c|c|c|c|c|}
\hline Model & Description & $\chi^{2}(d f)$ & $\mathrm{CFI}$ & RMSEA \\
\hline Model 1 & Six-factor ESEM & $3,321.413(1,705)^{\star \star}$ & .932 & .040 \\
\hline Model 2 & Six-factor CFA (selection of 5 items per scale and 10 for BIS) & $1,920.338(545)^{\star \star}$ & .903 & .065 \\
\hline Model 3 & Six-factor CFA (item 25 deleted) & $1,615.934(512)^{\star \star}$ & .921 & .060 \\
\hline Model 4 & Six-factor CFA (facets of BIS and FFS added) & $2,221.627(650)^{\star \star}$ & .898 & .063 \\
\hline Model 5 & Six-factor CFA (item 52 deleted) & $1,957.649(614)^{\star \star}$ & .911 & .060 \\
\hline
\end{tabular}

CFA = confirmatory factor analysis; CFI = comparative fit index; $x^{2}=$ chi square; $d f$ = degrees of freedom; ESEM = exploratory structural equation model; RMSEA = root mean square error of approximation. ${ }^{\star \star} p<.01$. 
Table 5. Pearson correlations and reliability for the Dutch B-RST-PQ scales (first row) and for the original RST-PQ scales (second row, Corr \& Cooper, 2016)

\begin{tabular}{lcccccc}
\hline & 1 & 2 & $3 a$ & $3 b$ & $3 c$ & $3 d$ \\
\hline 1. FFS & - & $.34^{\star \star}$ & $-.19 \star \star$ & .02 & .06 & .08 \\
& .44 & -.08 & .07 & .21 & .16 \\
2. BIS & & - & $-.23^{\star \star}$ & -.07 & $-.15^{\star \star}$ & $.12^{\star \star}$ \\
& & & -.06 & -.06 & .16 & .17
\end{tabular}

3. BAS

3a. RI

$.48^{\star \star} \quad .44^{\star \star} \quad .35^{\star \star}$

$.41 \quad .48 \quad .43$

3b. GDP

$.36^{* *}$

$.18^{* *}$

3c. RR

$.33 \quad .02$

$$
\text { 3c. RR }
$$$$
-.24^{* *}
$$

3d. IMP

\begin{tabular}{lllllll}
$\alpha$ & .66 & .92 & .79 & .79 & .67 & .73 \\
& .78 & .93 & .75 & .86 & .78 & .74 \\
$\omega$ & .66 & .92 & .79 & .79 & .67 & .74 \\
\hline
\end{tabular}

Note. $N=601 .{ }^{\star} p<.05,{ }^{\star \star} p<.01$. BAS = behavioral approach system; BIS $=$ behavioral inhibition system; $B-R S T-P Q=$ brief version of the RST-PQ; FFS = flight-freeze system; GDP = goal-drive persistence; IMP = impulsivity; RI = reward interest; $\mathrm{RR}=$ reward reactivity; RST-PQ = Reinforcement Sensitivity Theory of Personality Questionnaire.

Finally, Model $5^{2}$ of the brief RST-PQ included 12 items for BIS, six items for FFS, and five items for each BAS subscale apart from reward reactivity which comprised four items. Overall, strong Pearson correlation coefficients $(p<.01)$ were found between the B-RST-PQ scales and the long scales: FFS $(r=.93)$, BIS $(r=.97)$, reward interest $(r=.96)$, GDP $(r=.97)$, reward reactivity $(r=.78)$, and impulsivity $(r=.92)$.

Correlations between the Dutch B-RST-PQ scales were assessed using Pearson correlation coefficients (Table 5). The BAS subscales correlated similarly high $(r=.35-.48)$, except for impulsivity and GDP $(r=.18)$. The correlation between impulsivity and reward reactivity $(r=.24)$ was somewhat weaker.

\section{Reliability and Gender Differences}

To assess the internal consistency of the B-RST-PQ scales, Cronbach's $\alpha$ coefficients were calculated. The $\alpha$ coefficients were similar to those of the original RST-PQ scale (Table 5). McDonald's $\omega$ coefficients were assessed since this measure of reliability is less subject to the influence of the number of items in a scale, which is more the case for Cronbach's $\alpha$ coefficients. Omega coefficients ranged from .66 to .92 .
Gender difference analyses showed that the female sample scored higher on FFS, BIS, GDP, and reward reactivity (see ESM 3).

\section{Convergent and Divergent Validity of the B-RST-PQ}

The associations between the B-RST-PQ subscales and the personality and symptom measures are displayed in Table 6. A positive correlation was found between FFS and BIS (BIS/BAS scales; $r=.46)$ and neuroticism $(r=.34)$ and gender $(r=.35)$. In comparison, BIS correlated more strongly with BIS (BIS/BAS scales; $r=.59$ ) and neurot$\operatorname{icism}(r=.63)$. BIS also showed a strong connection to anxiety $(r=.50)$, whereas FFS did not $(r=.14)$. Finally, a significant negative correlation was found between BIS and age $(r=-.31)$. As mentioned before, all BAS subscales correlated moderately to strongly with the BAS subscales from Carver and White $(r=.30-.61)$ and with extraversion $(r=.39-.72)$. Reward interest showed a positive correlation with openness $(r=.31)$. Both GDP and reward reactivity correlated positive with conscientiousness $(r=.42$ and $r=.42$, respectively). Impulsivity correlated negatively with agreeableness $(r=-.27)$. Although the correlations might be somewhat more pronounced, a similar pattern to the long version is shown.

\section{Discussion}

We aimed to assess the psychometric properties of the original RST-PQ in a Dutch-speaking community sample. The results of the CFA confirmed the six-factor structure of the original questionnaire, with fit indices similar to those reported by Corr and Cooper (2016) and other translated versions of the RST-PQ (Eriksson et al., 2019; Krupic et al., 2016; Pugnaghi et al., 2018; Wytykowska et al., 2017). All subscales presented good internal consistency coefficients that are comparable to the original version. The associations between the RST-PQ and the other instruments supported expectations and confirmed the convergent validity of the Dutch version of the RST-PQ.

Since the CFA model did not obtain adequate model fit, a B-RST-PQ was constructed, consisting of 37 items. As expected, a clear six-factor structure with fewer crossloading items than the original RST-PQ was observed. These shortened scales of the B-RST-PQ correlated well with the original long scales, suggesting only a minimal loss of information. The six scales of the B-RST-PQ showed acceptable reliability coefficients.

\footnotetext{
2 The six-factor CFA was also estimated with ML (CFI = .847; RMSEA = .058) and ReML (CFI = .848; RMSEA = .055).
} 
Table 6. Pearson correlations between the Dutch B-RST-PQ and other measures of personality and symptoms

\begin{tabular}{|c|c|c|c|c|c|c|}
\hline & \multicolumn{6}{|c|}{ B-RST-PQ } \\
\hline & FFS & BIS & $\mathrm{RI}$ & GDP & RR & IMP \\
\hline \multicolumn{7}{|l|}{ BIS/BAS scales ${ }^{a}$} \\
\hline BIS & $.46^{\star \star}$ & $.59 \star \star$ & -.15 & -.05 & .02 & -.16 \\
\hline BAS - DR & -.06 & $<.01$ & $.52^{\star \star}$ & $.52 * \star$ & $.37 * \star$ & $.58 * \star$ \\
\hline BAS - FS & -.17 & .05 & $.57^{\star \star}$ & $.40 * \star$ & $.30 * *$ & $.61^{\star \star}$ \\
\hline $\mathrm{BAS}-\mathrm{RR}$ & .19 & .18 & $.31^{\star *}$ & $.38 * \star$ & $.47^{\star \star}$ & $.32^{\star \star}$ \\
\hline \multicolumn{7}{|l|}{ SCL-90 } \\
\hline Anxiety & .14 & $.50 * \star$ & -.07 & .03 & .07 & $.32^{\star \star}$ \\
\hline Phobic anxiety & .02 & .20 & .01 & -.01 & .09 & $.28 * \star$ \\
\hline \multicolumn{7}{|l|}{$B F l^{\circ}$} \\
\hline Openness & $-.22^{\star}$ & -.04 & $.31^{\star *}$ & .12 & .02 & .05 \\
\hline Conscientiousness & $.23^{\star}$ & -.13 & $.22^{\star}$ & $.42^{\star \star}$ & $.42^{\star \star}$ & .06 \\
\hline Extraversion & -.13 & $-.25^{\star}$ & $.72^{\star \star}$ & $.50 * \star$ & $.39 * \star$ & $.52^{\star \star}$ \\
\hline Agreeableness & $.21 *$ & -.14 & -.03 & .08 & .13 & $-.27 \star$ \\
\hline Neuroticism & $.34^{\star \star}$ & $.63^{* *}$ & -.08 & .06 & .08 & .12 \\
\hline Age & $-.08^{\star}$ & $-.31 * \star$ & $.13^{\star *}$ & -.02 & $.09 *$ & $<.01$ \\
\hline Sex & $.35^{\star \star}$ & $.12^{\star \star}$ & .01 & $.12^{\star \star}$ & $.17^{\star \star}$ & -.05 \\
\hline
\end{tabular}

BAS = behavioral approach system; BFI = Big Five Inventory; BIS = behavioral inhibition system; B-RST-PQ = brief version of the Rreinforcement Sensitivity Theory of Personality Questionnaire; DR = drive; FFS = flight-freeze system; FS = fun seeking; GDP = goal-drive persistence; IMP = impulsivity; RI = reward interest; $\mathrm{RR}=$ reward reactivity; $\mathrm{RR}=$ reward responsiveness; $\mathrm{SCL}-90=$ Symptom Checklist-90. aSample size $=112 .{ }^{\mathrm{b}}$ Sample size $=86 .{ }^{\circ}$ Sample size $=85 .{ }^{\star} p<$ $.05, * * p<.01$.

The correlation between reward reactivity and impulsivity was somewhat weaker for the B-RST-PQ. On the item level, it was noticed that the items that correlated most with impulsivity were deleted from the RR scale, which might be the cause for a less strong relationship between the two scales.

Concerning the convergent and divergent validity of the B-RST-PQ scales, the correlation pattern replicated that of the longer version, but somewhat more pronounced. Broadly, FFS and BIS correlated with BIS (BIS/ BAS scales) and neuroticism. As expected, FFS correlated weaker than BIS with the aforementioned scales, but this is more manifest in the brief version. Both scales differentiated in other associations as well: BIS correlated strongly positive with anxiety and negative with extraversion and age. FFS correlated positive with gender. Surprisingly, FFS no longer correlated with anxiety, which might contribute to the more clear differentiation of BIS and FFS.

The BAS subscales correlated well with their analog subscales from the BIS/BAS scales and with extraversion. Reward interest showed a positive correlation with openness, as GDP did to conscientiousness. The correlation between reward reactivity and conscientiousness was not assumed. However, earlier publications show the BIS/ BAS subscale of reward responsiveness to have a positive association with conscientiousness (Jackson \& Smillie, 2004; Segarra et al., 2014). Our results further support the premise that high RR scorers characterize individuals who can also control their impulses. Another correlation that was not expected was the moderate negative association between impulsivity and agreeableness. In most studies, results indicate a weaker link. This might just be a sample characteristic.

Based on the results of the present study, we can conclude that both the Dutch translation of the RST-PQ and the B-RST-PQ show good reliability and validity and that the B-RST-PQ also reached a good model fit.

Besides the strengths of this study, some limitations need to be addressed as well. The sample is not representative of the Dutch-speaking population and features an overrepresentation of female participants. We did not have access to a second, independent sample to verify our item selection. Moreover, the sample sizes used for convergent and divergent validity were unsatisfactory, which might have distorted the current findings. It is important to emphasize that there is a capitalization on chance and that these results might not be generalizable. A new study might benefit from a stratified and more representative sample.

A low-stakes setting like self-report within an experimental context might be more susceptible for social desirability. Additionally, the correlations can at least be 
partially ascribed to shared method variance. Future research should explore other methods beside self-report, such as interviewing or behavioral measures. The research could also benefit from assessing the psychometric properties of the questionnaire in other settings such as clinical populations or in an occupational context.

In sum, our study aimed to develop a Dutch version of the RST-PQ that could be used for research purposes in the Dutch-speaking community. The current findings extend the previous studies in which a similar model fit was found; similar reliability coefficients were reported; and divergent and convergent validity results correspond to expectations. A brief version of the Dutch RSTPQ was introduced, for which similar validity but a better model fit was established reflecting the concepts of the RST. This B-RST-PQ supports the extensive research employing RST as a major framework for the unified study of emotion, motivation, personality, and psychopathology.

\section{Electronic Supplementary Material}

The electronic supplementary material is available with the online version of the article at https://doi.org/ $10.1027 / 2698-1866 / \mathrm{a} 000004$

ESM 1. Factor loadings of the Dutch B-RST-PQ

ESM 2. The Dutch RST-PQ

ESM 3. Additional descriptive analyses

\section{References}

Arrindell, W. A., \& Ettema, H. (1981). Dimensionele structuur, betrouwbaarheid en validiteit van de Nederlandse bewerking van de Symptom Checklist (SCL-90): Gegevens gebaseerd op een fobische een "normale" populatie. Nederlands Tijdschrift voor de Psychologie en haar Grensgebieden, 36, 77-108.

Asparouhov, T., \& Muthén, B. (2009). Exploratory structural equation modeling. Structural Equation Modeling: A Multidisciplinary Journal, 16(3), 397-438. https://doi.org/10.1080/10705510903008204

Behr, D., \& Shishido, K. (2016). The translation of measurement instruments for cross-cultural surveys. In C. Wolf, D. Joye, T. W. Smith, \& Y. Fu (Eds.), The SAGE handbook of survey methodology (1st ed., pp. 269-288). SAGE Publications.

Bijttebier, P., Beck, I., Claes, L., \& Vandereycken, W. (2009). Gray's reinforcement sensitivity theory as a framework for research on personality-Psychopathology associations. Clinical Psychology Review, 29(5), 421-430. https://doi.org/10.1016/j.cpr.2009.04.002

Carver, C. S. (2004). Negative affects deriving from the behavioral approach system. Emotion, 4(1), 3-22. https://doi.org/10.1037/ 1528-3542.4.1.3

Carver, C. S., \& White, T. L. (1994). Behavioral inhibition, behavioral activation, and affective responses to impending reward and punishment: The BIS/BAS scales. Journal of Personality and Social Psychology, 67(2), 319-333. https://doi.org/10.1037/00223514.67.2.319

Corr, P. J. (2001). Testing problems in J. A. Gray's personality theory: A commentary on Matthews and Gilliland (1999). Personality and Individual Differences, 30(2), 333-352. https://doi. org/10.1016/S0191-8869(00)00028-3

Corr, P. J. (2006). Basic psychology. Understanding biological psychology. Blackwell Publishing.

Corr, P. J. (2008). The reinforcement sensitivity theory of personality. Cambridge University Press. https://doi.org/10.1017/ CB09780511819384

Corr, P. J. (2016). Reinforcement sensitivity theory of personality questionnaires: Structural survey with recommendations. Personality and Individual Differences, 89, 60-64. https://doi.org/ 10.1016/j.paid.2015.09.045

Corr, P. J., \& Cooper, A. J. (2016). The reinforcement sensitivity theory of personality questionnaire (RST-PQ): Development and validation. Psychological Assessment, 28(11), 1427-1440. https:// doi.org/10.1037/pas0000273

Corr, P. J., \& McNaughton, N. (2012). Neuroscience and approach/ avoidance personality traits: A two stage (valuation-motivation) approach. Neuroscience \& Biobehavioral Reviews, 36(10), 2339-2354. https://doi.org/10.1016/j.neubiorev.2012.09.013

Dunn, T. J., Baguley, T., \& Brunsden, V. (2014). From alpha to omega: A practical solution to the pervasive problem of internal consistency estimation. British Journal of Psychology, 105(3), 399-412. https://doi.org/10.1111/bjop.12046

Eriksson, L. J. K., Jansson, B., \& Sundin, Ö. (2019). Psychometric properties of a Swedish version of the reinforcement sensitivity theory of personality questionnaire. Nordic Psychology, 71(2), 134-145. https://doi.org/10.1080/19012276.2018.1516563

Eysenck, H. J. (1960). Behaviour therapy and the neuroses: Readings in modern methods of treatment derived from learning theory (1st ed.). Pergamon.

Gray, J. A. (1970). The psychophysiological basis of introversion-extraversion. Behaviour Research and Therapy, 8(3), 249-266. https://doi.org/10.1016/0005-7967(70)90069-0

Gray, J. A. (1982). The neuropsychology of anxiety: An enquiry into the functions of the septo-hippocampal system. Oxford University Press.

Gray, J. A., \& McNaughton, N. (2000). The neuropsychology of anxiety. Oxford University Press.

Harmon-Jones, E. (2003). Clarifying the emotive functions of asymmetrical frontal cortical activity. Psychophysiology, 40(6), 838-848. https://doi.org/10.1111/1469-8986.00121

Hu, L., \& Bentler, P. M. (1999). Cutoff criteria for fit indexes in covariance structure analysis: Conventional criteria versus new alternatives. Structural Equation Modeling: A Multidisciplinary Journal, 6(1), 1-55. https://doi.org/10.1080/ 10705519909540118

Jackson, C. J., \& Smillie, L. D. (2004). Appetitive motivation predicts the majority of personality and an ability measure: A comparison of BAS measures and a re-evaluation of the importance of RST. Personality and Individual Differences, 36(7), 1627-1636. https:// doi.org/10.1016/j.paid.2003.06.010

John, O. P., \& Srivastava, S. (1999). The big five trait taxonomy: History, measurement and theoretical perspectives. In L. Pervin \& O. P. John (Eds.), Handbook of personality: Theory and research (2nd ed., pp. 102-138). The Guilford Press.

Krupić, D. (2017). Empirical test of reinforcement sensitivity theory [Unpublished doctoral dissertation]. University of Rijeka.

Krupić, D., Corr, P. J., Ručević, S., Križanić, V., \& Gračanin, A. (2016). Five reinforcement sensitivity theory (RST) of personality questionnaires: Comparison, validity and generalization. 
Personality and Individual Differences, 97, 19-24. https://doi. org/10.1016/j.paid.2016.03.012

Ma-Kellams, C., \& Wu, M. S. (2020). Gender, behavioral inhibition/ activation, and emotional reactions to negative natural and social events. Personality and Individual Differences, 157, 109809. https://doi.org/10.1016/j.paid.2019.109809

Pickering, A. D., \& Smillie, L. D. (2008). The behavioural activation system: Challenges and opportunities. In P. J. Corr (Ed.), The reinforcement sensitivity theory of personality (1st ed., pp. 120-154). Cambridge University Press.

Pugnaghi, G., Cooper, A., Ettinger, U., \& Corr, P. J. (2018). The psychometric properties of the German language reinforcement sensitivity theory-personality questionnaire (RST-PQ). Journal of Individual Differences, 39(3), 182-190. https://doi.org/10.1027/ 1614-0001/a000262

Segarra, P., Poy, R., López, R., \& Moltó, J. (2014). Characterizing Carver and White's BIS/BAS subscales using the five factor model of personality. Personality and Individual Differences, 61-62, 18-23. https://doi.org/10.1016/j.paid.2013.12.027

Smillie, L. D., Pickering, A. D., \& Jackson, C. J. (2006). The new reinforcement sensitivity theory: Implications for personality measurement. Personality and Social Psychology Review, 10(4), 320-335. https://doi.org/10.1207/s15327957pspr1004_3

Wolpe, J., \& Lang, P. J. (1964). A fear survey schedule for use in behavior therapy. Behaviour Research \& Therapy, 2(1), 27-30. https://doi.org/10.1016/0005-7967(64)90051-8

Wytykowska, A., Fajkowska, M., Domaradzka, E., \& Jankowski, K. S. (2017). Construct validity of the Polish version of the reinforcement sensitivity theory-personality questionnaire. Personality and Individual Differences, 109, 172-180. https://doi.org/10.1016/j.paid. 2016.12.054

\section{History}

Received January 26, 2020

Revision received June 10, 2020

Accepted August 12, 2020

Published online September 24, 2020

\section{Acknowledgements}

We would like to thank Prof. Dr. Koen Luyckx, Prof. Dr. Cilia Witteman, Dr. Glenn Kiekens, Dr. Annabel Bogaerts, and Dr. Tinne Buelens for taking part in the translation of the Dutch version of the RST-PQ into English.

\section{Funding}

This research did not receive any specific grant from funding agencies in the public, commercial, or not-for-profit sectors.

\section{ORCID}

Serafine Dierickx

(D) https://orcid.org/0000-0001-9406-8919

Dirk Smits

(iD) https://orcid.org/0000-0001-5542-3252

Penelope Hasking

(D) https://orcid.org/0000-0002-0172-9288

\section{Serafine Dierickx}

Faculty of Psychology and Educational Sciences

KU Leuven

Tiensestraat 102

3000 Leuven

Belgium

serafinedierickx@gmail.com 